\title{
RESEÑA: CUATRO OBRAS POLÍTICAMENTE YNCORRECTAS. JUANA ESCABIAS ${ }^{1}$
}

\author{
Santiago Ruiz Omeñaca ${ }^{2}$
}

\begin{abstract}
Juana Escabias, Cuatro obras políticamente yncorrectas, con prólogo de Eduardo Pérez Rasilla. Madrid: Esperpento Ediciones Teatrales, 2015. ISBN: 9788494402937.
\end{abstract}

Bajo el título de Cuatro obras políticamente yncorrectas, publica Juana Escabias cuatro piezas teatrales de muy diferente índole, vinculadas solamente por el denominador común de estar protagonizadas por mujeres. Cautivas, No le cuentes a mi marido que sueño con otro hombre... cualquiera, WhatsApp y Crimen imperfecto son los cuatro textos que conforman este libro publicado por Esperpento Ediciones Teatrales, editorial surgida recientemente con un explícito lema: Una editorial de Teatro para el Teatro.

El volumen se inicia con un excelente prólogo de Eduardo Pérez Rasilla en el que se manifiesta el calado y el vigor de su dominio sobre el hecho escénico y su certera y brillante capacidad de indagación en el teatro como fenómeno social y literario. Desde las primeras líneas ya destaca el prologuista que los cuatro textos, formalmente, presentan rasgos muy distintos entre sí. Sobre la autora, dice: "La mirada desde la que están escritos parece revelar un objetivo de análisis, un deseo de hurgar en las heridas sociales para procurar un remedio a esas dolencias, una voluntad de denuncia. Es decir, han sido pensados desde una implicación con lo social y desde un compromiso con lo político".

La presentación de Pérez Rasilla continúa con un análisis individualizado de cada una de las obras sobre el que se entrecruzan de forma permanente diversos planos de

\footnotetext{
${ }^{1}$ Fecha de recepción: 05/06/2015.

Fecha de aceptación: 20/06/2015.

${ }^{2}$ Profesor en el CIDAM, Centro de Información, Documentación y Atención a la Mujer, Madrid; $\bowtie$ iagoruiz@gmail.com
} 
exploración. Los textos se suceden acto seguido: Cautivas (un texto reivindicativo de la "memoria histórica española" protagonizado por un grupo de presas políticas hacinadas en las cárceles franquistas), No le cuentes a mi marido que sueño con otro hombre... cualquiera (un violento enfrentamiento entre un fracasado matrimonio), WhatsApp (historia de adolescentes contada a golpe de mensaje telefónico) y Crimen Imperfecto (monólogo en el que Luci, víctima de un sutil maltrato difícil de detectar, pasa de la ignorancia al conocimiento sobre su propia realidad experimentando un auténtico proceso de metabolé).

Diferentes estructuras, diferentes protagonistas, diferentes perspectivas existenciales, diferentes lenguajes, diferentes manera de plasmar el conflicto existencial que palpita en cada una de las obras... pero una misma y única temática (la violencia), una misma y única protagonista (la mujer).

El libro es un ex profeso ejercicio de habilidad estructural, cualidad que la caracteriza como escritora y ha sido señalado en diversas ocasiones por la crítica. Ya en 1997, cuando Escabias publicó su primer libro, la extraordinaria maestra del teatro que fue Carla Matteini (lamentablemente ya fallecida), celebraba la valentía de la nobel escritora que buscaba el riesgo y trabajaba sin red:

Y se muestra tan segura de su osadía al meterse en semejantes embrollos, desdeñando, o más bien buscando, más y más riesgo, tan convencida de haber escrito lo que quería escribir -lo que es un lujo de libertad de opción y de indiferencia hacia los dictados de "lo que conviene", afortunadamente sacrificado a lo que ella cree que hay que hacer- que te rindes ante su valor, su espíritu profundamente libre e independiente de influencias y normas. (1997: 44-45)

A propósito de ese mismo trabajo, el riguroso crítico Luis de la Peña mostraba su satisfacción por el rigor asumido por la autora:

La escritura de Escabias se fundamenta en un texto dominado por la ironía de manera distanciadora y crítica, y en un trabajo formal fragmentario de cuya pirueta estructural la autora sale sobradamente airosa. Pero la asunción de ese riesgo en la construcción formal tendría poco interés si no se tradujese en un auténtico mundo 
novelesco. El acierto de Escabias reside en encontrar el modo preciso para contar la historia de unos seres cuya identidad decae en los abismos de la vulgaridad, historia que se sigue a través de una intriga cuyos elementos forman parte de lo cotidiano". (1997: 10)

Respecto a la voluntad de Juana Escabias de convertir su teatro en un escaparate desde el que hurgar en las heridas más profundas de nuestra sociedad, apuntada por Pérez Rasilla en el prólogo del libro, otros autores e investigadores coinciden en ese aspecto, destacado como peculiaridad de la autora. Francisco Gutiérrez Carbajo, afirmaba en el prólogo a Historia de un Imbécil e Interiores que "el compromiso con la realidad, con el texto y con la representación constituye el rasgo más singular del teatro de Juana Escabias". Jerónimo López Mozo, en el prólogo de Voracidad de los parques y Deseo manifestaba que "Escabias es, pues, una autora interesada en cuanto afecta al hombre de nuestro tiempo en su doble condición de individuo y ser social”. Juan Ignacio García Garzón, por su parte, insistía en esa particularidad extendiéndola al terreno de la acción dramática. La autora conoce muy bien el terreno que pisa, domina los secretos de eso que en la jerga de los escenarios se llama carpintería teatral y dibuja con pulso certero a sus personajes, que son seres que uno puede imaginar de carne y hueso, creíbles, llenos de verdad escénica.

Cuatro obras políticamente yncorrectas es un cuarteto de textos de perspicaz planteamiento elaborados por la reputada dramaturga Juana Escabias, que en su doble condición de autora y directora escénica los ha sabido crear desde la escena y para la escena, un libro que por sí solo ya se ha creado un lugar en la historia del teatro español contemporáneo.

\section{Referencias bibliográficas}

De la Peña, Luis. 1997. El País, 22 de marzo de 1997, Suplemento Babelia: 10. 
Gutiérrez Carbajo, Francisco. 2010. "La realidad y la representación en Juana Escabias", prólogo a Historia de un Imbécil e Interiores. Juana Escabias. Madrid: Huerga y Fierro Editores. 7-10.

López Mozo, Jerónimo. 2013. "Radiografías de seres humanos”, prólogo a Voracidad de los parques y Deseo. Juana Escabias. Madrid: Huerga y Fierro Editores. 7-15.

Pérez Rasilla, Eduardo. 2015. "Prólogo”. Cuatro obras políticamente yncorrectas. Juana Escabias. Madrid: Esperpento Ediciones Teatrales.

Matteini, Carla. 1997. Página Abierta, no 71/abril 1997: 44-45. 